\title{
A high-throughput method for isolation of salicylic acid metabolic mutants
}

\author{
George Marek ${ }^{\dagger}$, Ryan Carver ${ }^{\dagger}$, Yezhang Ding, Deepak Sathyanarayan, Xudong Zhang, Zhonglin Mou ${ }^{*}$
}

\begin{abstract}
Background: Salicylic acid (SA) is a key defense signal molecule against biotrophic pathogens in plants. Quantification of SA levels in plants is critical for dissecting the SA-mediated immune response. Although HPLC and GC/MS are routinely used to determine SA concentrations, they are expensive and time-consuming. We recently described a rapid method for a bacterial biosensor Acinetobacter sp. ADPWH_lux-based SA quantification, which enables high-throughput analysis. In this study we describe an improved method for fast sample preparation, and present a high-throughput strategy for isolation of SA metabolic mutants.

Results: On the basis of the previously described biosensor-based method, we simplified the tissue collection and the SA extraction procedure. Leaf discs were collected and boiled in Luria-Bertani (LB), and then the released SA was measured with the biosensor. The time-consuming steps of weighing samples, grinding tissues and centrifugation were avoided. The direct boiling protocol detected similar differences in SA levels among pathogeninfected wild-type, npr1 (nonexpressor of pathogenesis-related genes), and sid2 (SA induction-deficient) plants as did the previously described biosensor-based method and an HPLC-based approach, demonstrating the efficacy of the protocol presented here. We adapted this protocol to a high-throughput format and identified six npr1 suppressors that accumulated lower levels of SA than npri upon pathogen infection. Two of the suppressors were found to be allelic to the previously identified eds5 mutant. The other four are more susceptible than $n p r 1$ to the bacterial pathogen Pseudomonas syringae pv. maculicola ES4326 and their identity merits further investigation.

Conclusions: The rapid SA extraction method by direct boiling of leaf discs further reduced the cost and time required for the biosensor Acinetobacter sp. ADPWH_lux-based SA estimation, and allowed the screening for npr1 suppressors that accumulated less SA than nprl after pathogen infection in a high-throughput manner. The highly efficacious SA estimation protocol can be applied in genetic screen for SA metabolic mutants and characterization of enzymes involved in SA metabolism. The mutants isolated in this study may help identify new components in the SA-related signaling pathways.
\end{abstract}

\section{Background}

Salicylic acid (SA) is a key signaling molecule in plant defense against biotrophic pathogens [1,2]. Upon pathogen attack, SA accumulates in plant cells $[3,4]$. Prevention of SA accumulation leads to disease susceptibility [5], whereas treatment with SA confers resistance to a variety of biotrophic pathogens [6,7]. Thus, understanding the mechanisms underlying SA accumulation is critical in the study of plant immunity.

\footnotetext{
* Correspondence: zhlmou@ufl.edu

+ Contributed equally

Department of Microbiology and Cell Science, University of Florida, P.O. Box 110700, Gainesville, FL, 32611, USA
}

(c) 2010 Marek et al; licensee BioMed Central Ltd. This is an Open Access article distributed under the terms of the Creative Commons Attribution License (http://creativecommons.org/licenses/by/2.0), which permits unrestricted use, distribution, and reproduction in any medium, provided the original work is properly cited.
Nawrath and Métraux [8] performed a genetic screen for Arabidopsis mutants that do not accumulate SA after pathogen infection and identified two genetic loci, SID1/EDS5 and SID2/EDS16, which were later shown to encode a chloroplast MATE (multidrug and toxin extrusion) transporter [9] and an SA biosynthetic enzyme ICS1 (isochorismate synthase) [10], respectively. In the screen, Nawrath and Métraux used an HPLC-based method to quantify the SA levels in the pathogeninfected leaf tissues from about 4,500 individual $\mathrm{M}_{2}$ plants. Because the HPLC-based method involves extraction of SA in organic solvents, evaporation of organic solvents, chromatographic purification and detection by fluorescence spectroscopy $[11,12]$, it is 
extremely costly and time-consuming. To screen for more SA metabolic mutants, a much faster and less expensive method is needed.

Huang et al. recently developed an SA biosensor, named Acinetobacter sp. ADPWH_lux [13]. This strain is derived from Acinetobacter sp. ADP1, and contains a chromosomal integration of a salicylate-inducible lux$C D A B E$ operon. The operon encodes a luciferase (LuxA and LuxB) and the enzymes that produce its substrate (LuxC, LuxD and LuxE) so cells that express the cluster emit the 490-nm light spontaneously [14]. The biosensor is highly specific to SA, methyl-SA, and the synthetic SA derivative acetylsalicylic acid [13], thus suitable for the quantification of SA from crude plant extracts.

We previously described an approach for the simultaneous quantification of free and glucose conjugated SA from Arabidopsis leaf extracts using Acinetobacter sp. ADPWH_lux [15]. Here we present a further shortened protocol for the estimation of SA levels in pathogen-infected leaf tissue. Using the protocol described, we have performed a genetic screen for suppressors of the $\operatorname{npr} 1$ (nonexpressor of pathogenesis-related genes) mutant that hyperaccumulates SA during pathogen infection $[16,17]$.

\section{Results}

Rapid Extraction of SA by Direct Boiling of Leaf Discs

The method we previously described comprises leaf tissue collection (weighing samples), grinding, extraction in LB or acetate buffer, and centrifugation [15]. The resulting crude leaf extract is then mixed with a culture of the SA biosensor in a 96-well cell culture plate, and incubated at $37^{\circ} \mathrm{C}$ for one hour. The luminescence is then determined. Compared with the conventional HPLC or GC/MS method [11,18], the biosensor-based method is much faster and requires little tissue (as few as 2-3 leaves) [15]. However, the tissue collection (especially weighing samples) and the extraction procedure are still time-consuming. To search for an even faster method, we collected leaf discs $(0.7 \mathrm{~cm}$ in diameter, omitting weighing the samples) with a hole punch from the bacterial pathogen Pseudomonas syringae pv. maculicola (Psm) ES4326-infected leaves of wild-type Col-0, npr 1 and sid2 plants. We used pathogen-infected Col-0, $n p r 1$ and sid2 plants as samples because they contain significantly different levels of SA $[8,17]$. Each leaf disc was placed in $200 \mu \mathrm{L}$ of LB in a $1.5-\mathrm{mL}$ eppendorf tube, and boiled at $95^{\circ} \mathrm{C}$ for 20 minutes. The LB extracts were cooled down to room temperature, and then mixed with the SA biosensor and incubated at $37^{\circ} \mathrm{C}$ for one hour. The luminescence was then determined. We found that SA was readily extracted by the direct boiling of leaf discs. As shown in Figure 1A, the pathogen-infected Col-0 and npr1 samples had significantly higher
A

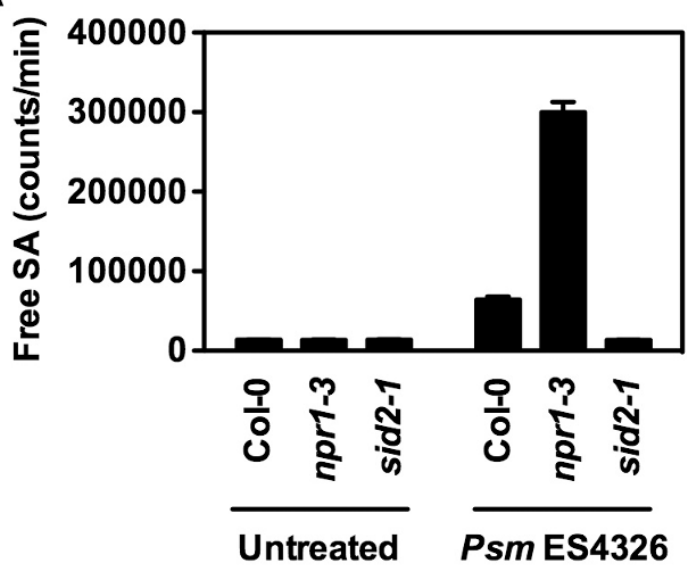

B

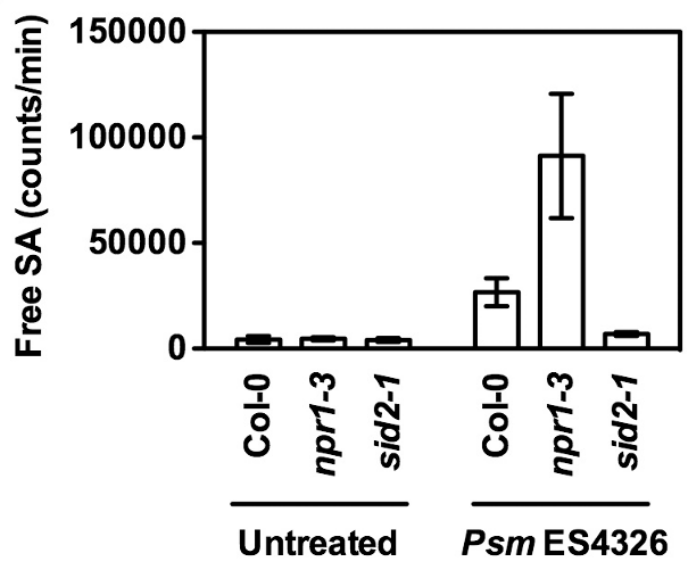

C

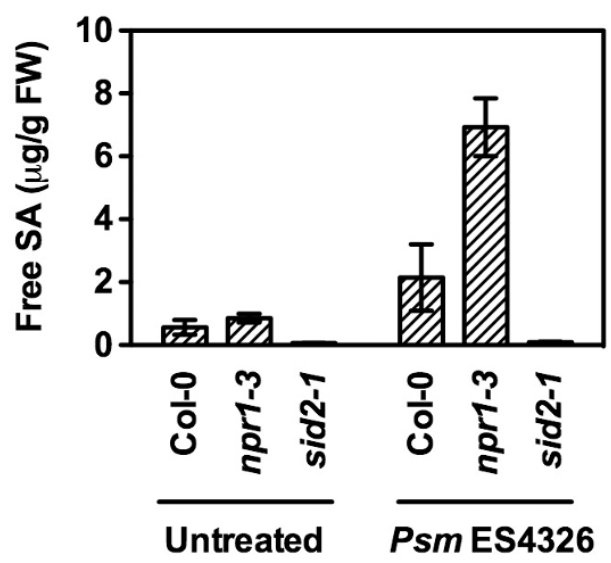

Figure 1 The direct boiling method in comparison with the previously described biosensor- and HPLC-based methods. (A) Luminescence from Psm ES4326-infected Col-0, npr1 and sid2 detected by the direct boiling method. (B) Luminescence from Psm ES4326-infected Col-0, npr1 and sid2 detected by the previously described biosensor-based method. (C) Free SA levels in Psm ES4326-infected Col-0, npr 1 and sid2 detected by the HPLC-based method. Values are the mean of 8 samples $(\mathbf{A}), 6$ samples read in triplicate (B), and 4 samples $(\mathbf{C})$ with standard deviation. 
luminescence than uninfected samples, whereas the sid2 samples just had background luminescence regardless of whether they were infected or not. Furthermore, the luminescence emitted by the infected npr 1 samples was significantly stronger than that emitted by the infected Col-0 samples (Figure 1A). The differences among Col0 , npr 1 and sid2 were very similar to those revealed by the previously described biosensor-based method and the HPLC-based approach (Figures $1 \mathrm{~B}$ and $1 \mathrm{C}$ ). These results suggest that the direct boiling method is able to detect the differences in SA levels among different genotypes, thus suitable for genetic screens for mutants with altered SA levels.

\section{High-Throughput Screening for SA Metabolic Mutants}

We adapted the direct boiling protocol to a highthroughput format competent for genetic screens. The strategy is schematically described in Figure 2A and a detailed protocol is presented in Additional file 1. Again, we used Col-0, npr 1 and sid2 to test the efficacy of the strategy. Seedlings of Col-0, npr 1 or sid2 were transplanted into one third (32 pots) of a 96-pot tray
(Figure 2B). Three weeks later, half of the plants of each genotype were inoculated with Psm ES4326 (Figure 2B). To save the time spent on inoculation, only one leaf on each plant was inoculated. Twenty-four hours later, a leaf disc from each inoculated leaf was collected using a hole punch, and placed into $200 \mu \mathrm{L}$ of LB in a corresponding well of a 96-well PCR plate. After all 96 leaf discs (from the 96 plants in Figure 2B) were collected and placed into the 96 wells, the PCR plate was put in a PCR machine and heated at $95^{\circ} \mathrm{C}$ for 20 minutes. The extracts were cooled down to room temperature, and $50 \mu \mathrm{L}$ of each extract was added into a corresponding well in a black 96-well culture plate loaded with $50 \mu \mathrm{L}$ of a freshly prepared biosensor culture in each well. After incubation at $37^{\circ} \mathrm{C}$ for 1 hour in the dark, luminescence was assayed using a microplate luminometer. As shown in Figure 2C, the differences in SA levels among the three genotypes were clearly detected using the "96-pot tray/96-well PCR plate/96-well culture plate" format.

We then attempted to set up a mutant screen aimed at identifying new components involved in regulating
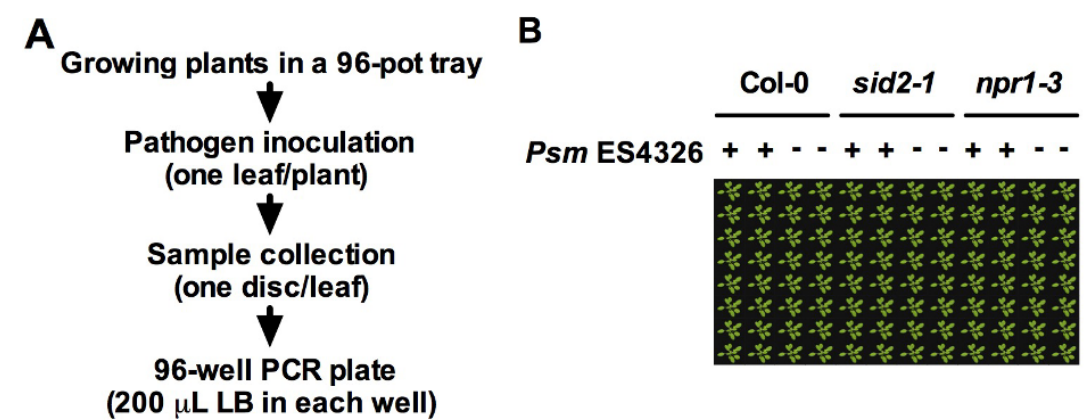

(200 $\mu \mathrm{L}$ LB in each well)

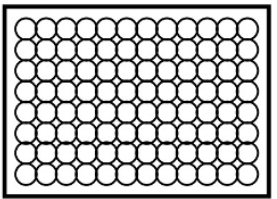

Boiling at $95^{\circ} \mathrm{C}$ for $20 \mathrm{~min}$ in a 96-well PCR machine $\checkmark$

96-well black culture plate (50 $\mu \mathrm{L}$ of biosensor culture in each well)
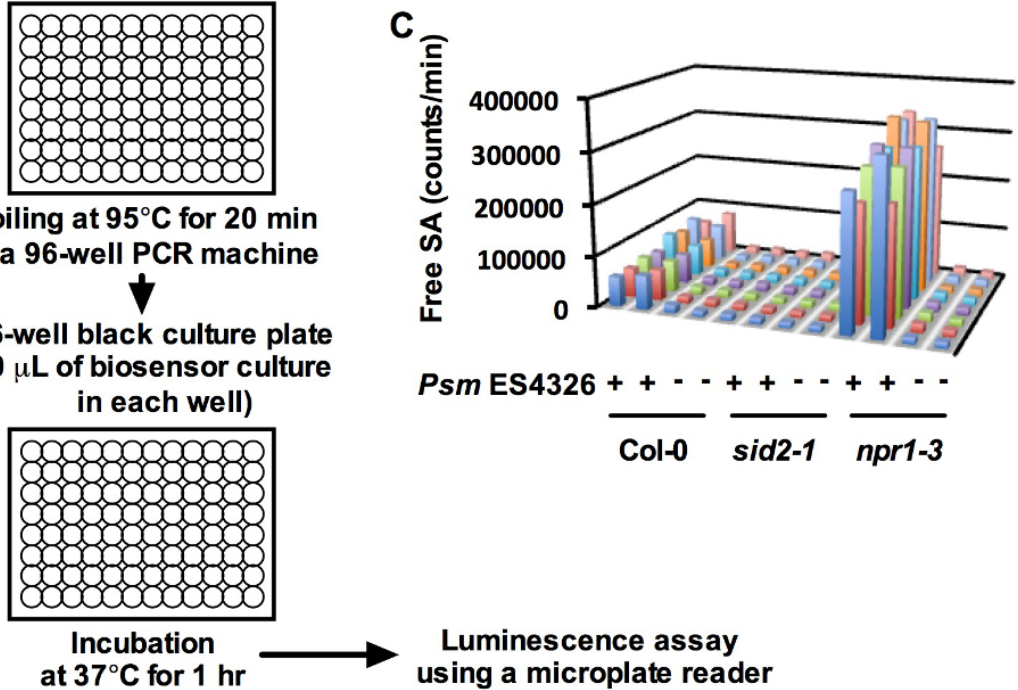

Luminescence assay using a microplate reader

Figure 2 High-throughput strategy for isolation of SA metabolic mutants. (A) Schematic of the "96-pot tray/96-well PCR plate/96-well culture plate" screen strategy. (B) Col-0, npr1 and sid2 plants grown in a 96-cell tray treated with or without Psm ES4326. (C) Luminescence from the Col-0, nprl and sid2 plants in (B) treated with or without Psm ES4326. 
SA accumulation. Since the $n p r 1$ mutant accumulates significantly higher levels of SA than wild type during pathogen infection, and NPR1 is a key positive regulator of SA-mediated immune responses [19-21], we reasoned that $n p r 1$ suppressors, which accumulate less pathogeninduced SA than $n p r 1$, would help uncover important regulators of plant immunity. We therefore decided to use the npr1 mutant as starting material for the screen.

One gram of $n p r l$ seeds were treated with ethyl methanesulfonate (EMS) and sown on soil. $\mathrm{M}_{2}$ seeds were collected in pools when the $M_{1}$ plants matured. After germination, $\mathrm{M}_{2}$ seedlings were transplanted into 96-pot trays and screened as described in Figure 2A. So far, approximately $10,000 \mathrm{M}_{2}$ plants have been screened. Figure 3 shows the luminescence from the plants in a randomly selected tray in the primary screen. The primary screen has identified 35 putative $n p r 1$ suppressors.

The putative suppressors were re-screened using the direct boiling protocol. In the secondary screen, three $\mathrm{M}_{3}$ plants from each putative suppressor were assayed. As shown in Figure 4, six putative suppressors had lower luminescence than $n p r 1$.

\section{Confirmation of the Putative SA Metabolic Mutants Using HPLC}

To further confirm that the suppressors accumulate less SA than $n p r 1$ after pathogen infection, we measured SA levels in the suppressors using HPLC. As shown in Figure 5, after Psm ES4326 infection, all six suppressors accumulated lower levels of both free and total SA than npr1, suggesting that the suppressors contain mutations that modified the SA accumulation pathway in npr1. Interestingly, suppressors 62 and 69 accumulated very low levels of SA, similar to the previously characterized eds5 and sid 2 mutant. To further characterize these two suppressors, we measured Psm ES4326-induced SA levels in the $F_{1}$ plants of the following crosses: $62 \times 69$, $62 \times n p r 1,69 \times n p r 1,62 \times e d s 5,62 \times \operatorname{sid} 2,69 \times e d s 5$,

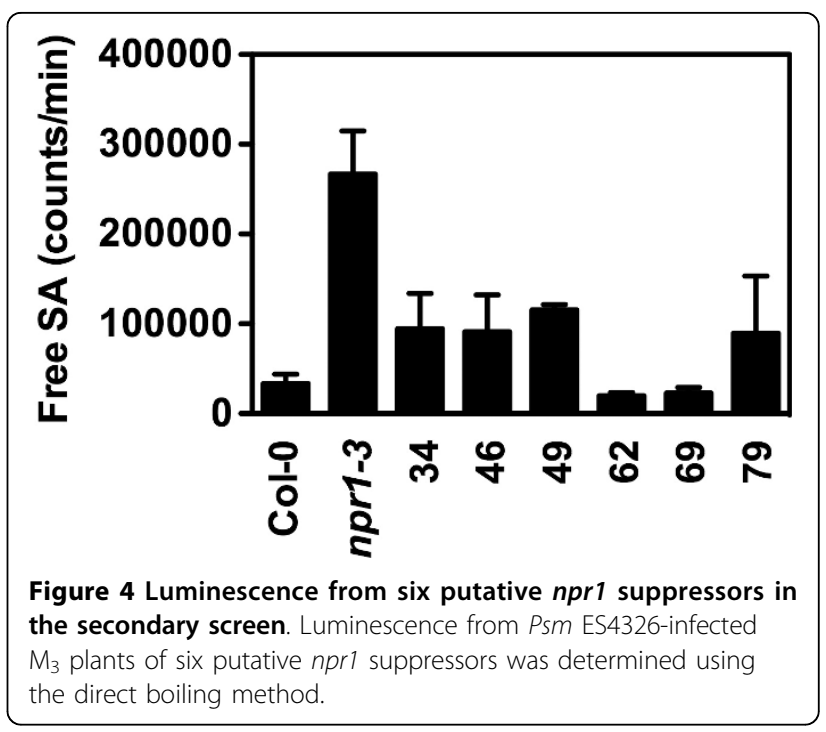

and $69 \times$ sid2. As shown in Figure 6, after Psm ES4326 infection, the $F_{1}$ plants of $62 \times 69$ accumulated similar levels of SA as 62 and 69, whereas the $F_{1}$ plants of $62 \times$ $n p r 1$ and $69 \times n p r 1$ had similar amounts of SA as npr1, suggesting that 62 and 69 are allelic and contain a recessive mutation, since the 62 and 69 alleles will be heterozygous in the $F_{1}$ Plants. Furthermore, the $F_{1}$ plants of $62 \times$ eds 5 and $69 \times$ eds 5 accumulated similar levels of SA as eds5, whereas the $F_{1}$ plants of $62 \times \operatorname{sid} 2$ and $69 \times$ sid 2 had similar amounts of SA as wild type, indicating that suppressors 62 and 69 are alleles of the eds 5 mutant.

To identify the genetic mutations in 62 and 69 , the open reading frames of the two alleles of EDS5 were sequenced. The allele 62 carries a transition mutation converting a TGG to a premature stop condon (TGA) at nucleotide 753 of the coding region, whereas the 69 mutation is caused by a G-to-A transition in the AG from the splice acceptor site in intron 5, which may lead to an abnormal splicing at the border of intron

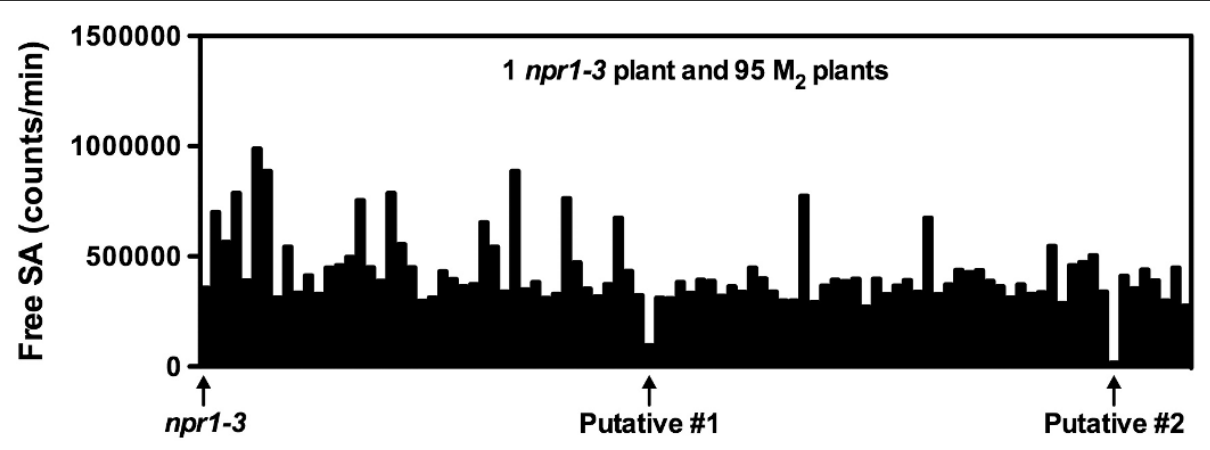

Figure 3 Luminescence from a randomly picked tray of plants in the primary screen. Luminescence from Psm ES4326-infected $M_{2}$ plants was determined using the direct boiling method in a "96-pot tray/96-well PCR plate/96-well culture plate" format. Arrows indicate the putative nprl suppressors. 


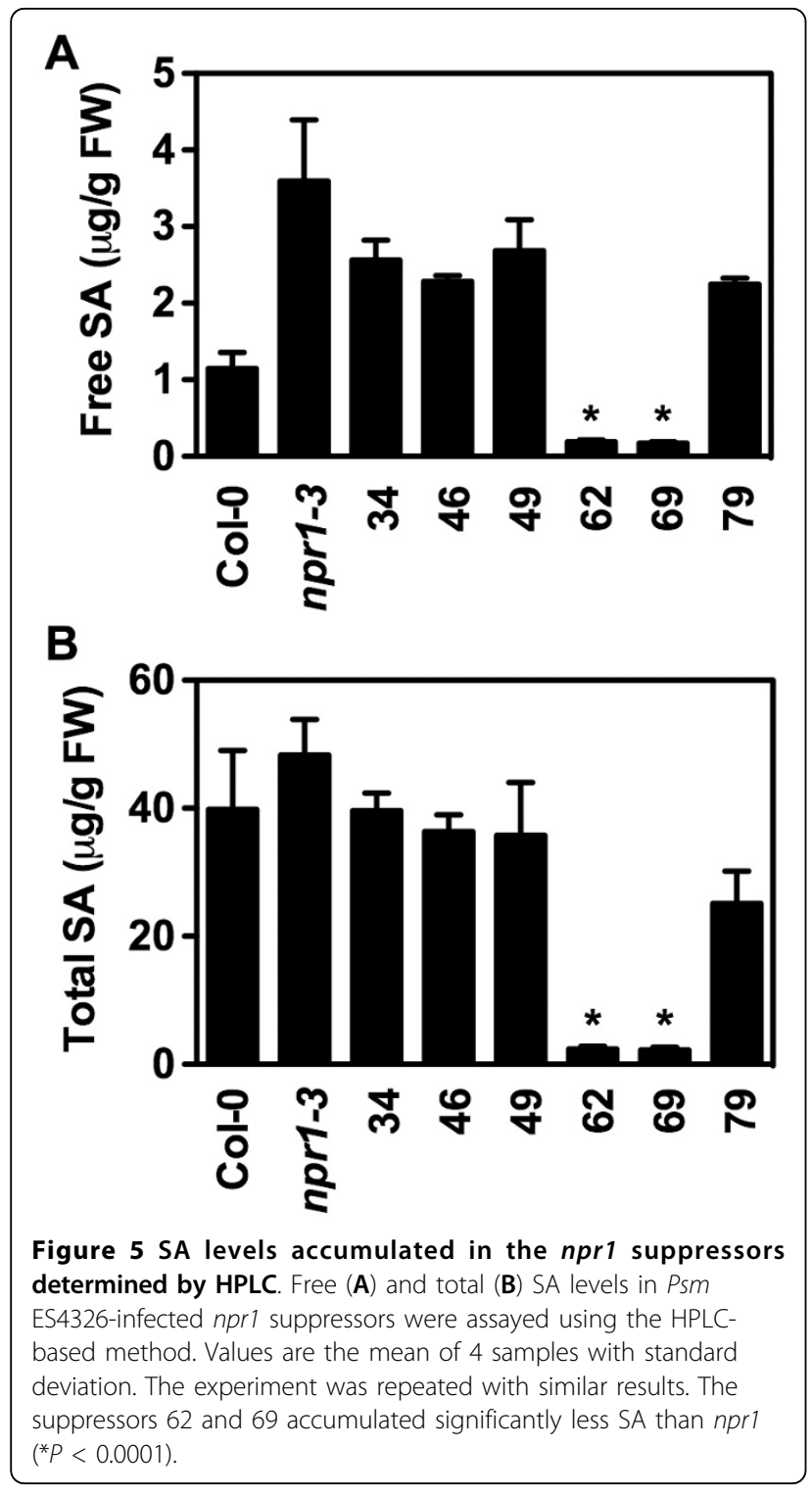

5/exon 6. These results indicate that the mutant screen identified two new alleles of the previously isolated eds 5 mutants [9].

Pathogen Resistance Test for the SA Metabolic Mutants To test whether the genetic mutations in the SA metabolic mutants affect pathogen resistance, we inoculated npr1-3 and the four mutants, 34, 46, 49, and 79, with the bacterial pathogen Psm ES4326. The eds5 alleles, 62 and 69, were excluded since eds5 has been well characterized [9]. The in planta growth of Psm ES4326 was monitored three days after inoculation. As shown in Figure 7, Psm ES4326 grew significantly more in the SA metabolic mutants than in npr1-3. The growth of Psm ES4326 in 49 was 10 -fold higher than in npr1-3. This result is significant since $n p r 1-3$ is already highly
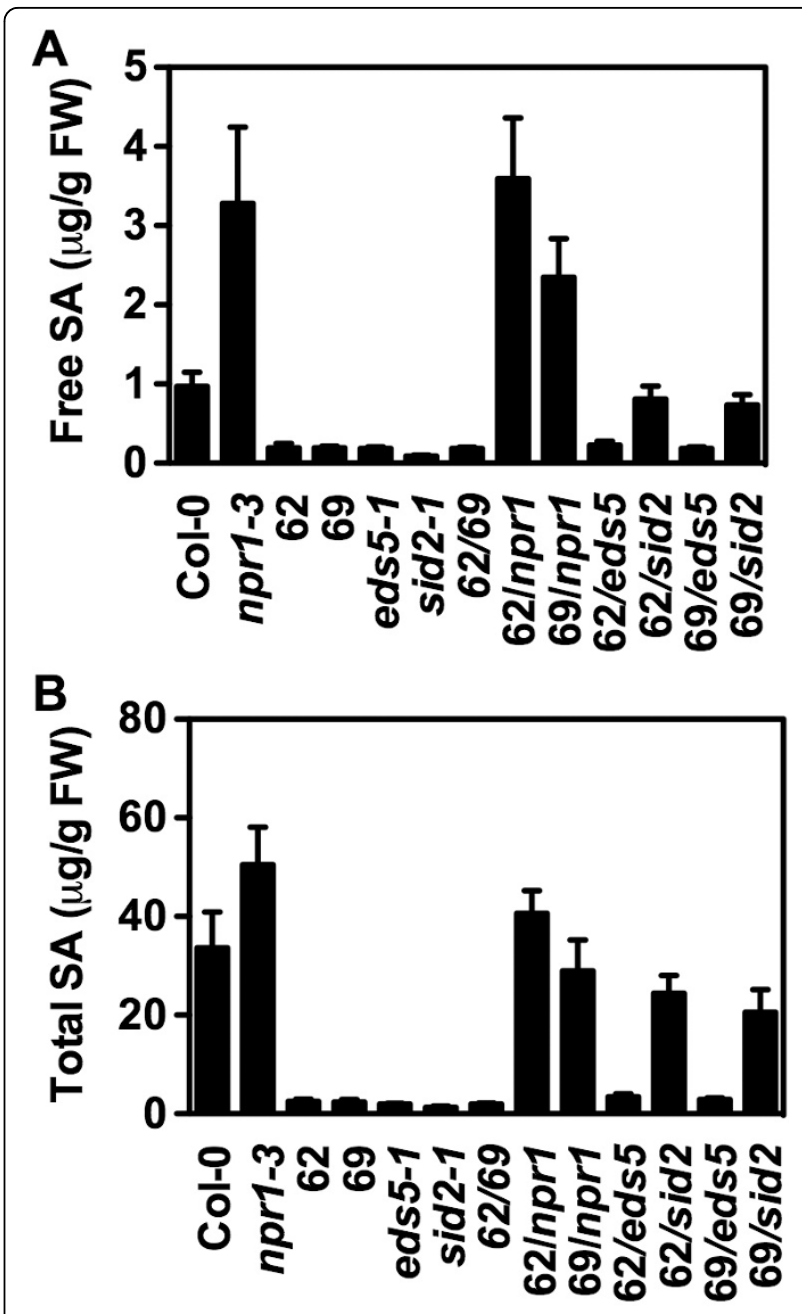

Figure 6 SA levels accumulated in the $F_{1}$ plants determined by HPLC. Free (A) and total (B) SA levels in PSm ES4326-infected $F_{1}$ plants of different crosses among 62,69, npr1, eds5, and sid2 were assayed using the HPLC-based method. Values are the mean of 4 samples with standard deviation. The experiment was repeated with similar results.

susceptible to Psm ES4326 [16], demonstrating that the high-throughput method developed in this study is valuable in identifying new components in the SA-mediated defense signaling pathway.

\section{Conclusions}

Here we present a direct boiling protocol for the rapid estimation of SA from plant tissue using the SA biosensor Acinetobacter sp. ADPWH_lux. This protocol is much faster and less expensive than the previously described biosensor-based approaches $[13,15]$. The fast sample preparation procedure, which comprises inoculation of one leaf on each plant, collection of leaf discs, and boiling in LB, significantly reduced the time spent on inoculation, tissue collection, grinding and centrifugation. 


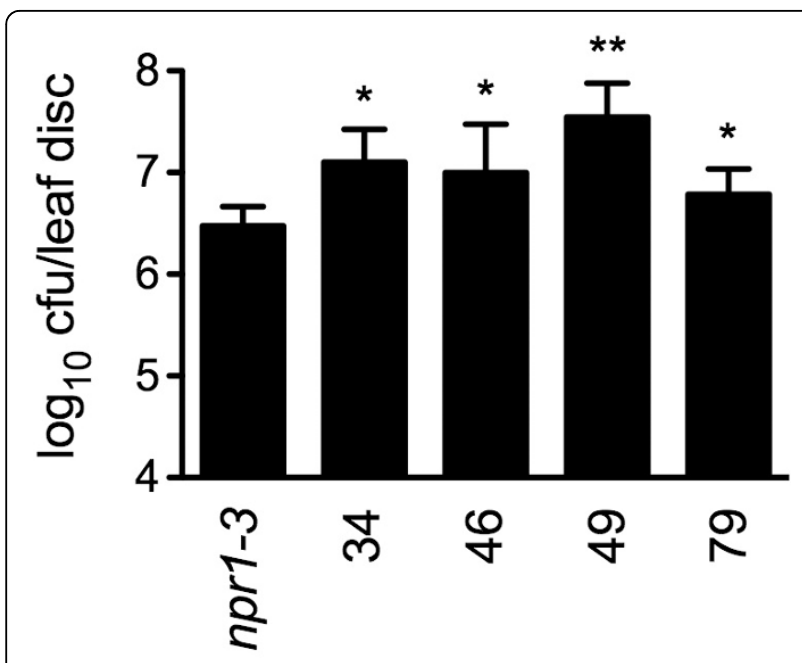

Figure 7 Pathogen growth in the SA metabolic mutants. Leaves of 4-week-old plants were inoculated with Psm ES4326 $\left(\mathrm{OD}_{600}=\right.$ 0.0001). The in planta bacterial titers were determined 3 days postinoculation. Cfu, colony-forming units. Data represent the mean of 8 independent samples with standard deviation. Psm ES4326 grew significantly more in $34,46,49$, and 79 than in $n p r 1-3\left({ }^{*} P<\right.$ 0.05 , $\left.{ }^{* *} P<0.002\right)$. The experiment was repeated three times with similar results.

This method was not designed to accurately determine the SA concentration. Rather, it is intended to estimate SA levels for rapid genetic screens with significant reductions in cost and processing time. We acknowledge that SA levels induced by Psm ES4326 infection can vary quite a lot among individuals of the same genotype, depending on plant growth conditions. Additionally, this method may not be sensitive enough in some applications, such as time-course quantifications of SA levels with pathogen infection. However, the successful genetic screen for suppressors of the npr 1 mutant has demonstrated the efficacy of this high-throughput strategy. We hope that the methodology presented in this study can help saturate the genetic screens for SA metabolic mutants, which in turn will facilitate a more thorough understanding of this important plant defense molecule [22,23].

\section{Methods}

\section{Plant material and pathogen infection}

The wild type used was the Arabidopsis thaliana (L.) Heynh. Columbia (Col-0) ecotype, and the mutant alleles used were npr1-3 [19], eds5-1 [9] and sid2-1 [8]. EMS mutagenesis was performed as described in [24]. Briefly, one gram of npr1-3 seeds were placed in $25 \mathrm{~mL}$ of $0.2 \%$ EMS $(\mathrm{v} / \mathrm{v})$ in a $50-\mathrm{mL}$ Falcon tube and incubated on a rocking platform for 15 hours. After the seeds were washed eight times with water, they were suspended in $0.1 \%$ agarose and sown on soil. $\mathrm{M}_{2}$ seeds were collected in pools when the $M_{1}$ plants reached to maturity. The $\mathrm{M}_{2}$ plants were germinated, transplanted to 96 -pot trays, and then grown at $22 \sim 25^{\circ} \mathrm{C}$ under a 16 $\mathrm{hr}$ light/8 hr dark regime for three weeks. Infection of plants with Psm ES4326 was performed as described previously [25]. One leaf on each plant was infiltrated with a suspension of Psm ES4326 (OD $600=0.001)$.

\section{Preparation of crude extract}

Twenty-four hours after Psm ES4326 infection, a leaf disc was collected from each infected plant using a hole punch and placed in $200 \mu \mathrm{l}$ of LB in a well of a 96-well PCR plate. The plate was then heated at $95^{\circ} \mathrm{C}$ for 20 min in a PCR machine and cooled down to room temperature.

\section{Detection of salicylic acid using Acinetobacter sp. ADPWH_lux and HPLC}

An overnight culture of Acinetobacter sp. ADPWH_lux was diluted in $37^{\circ} \mathrm{C} \mathrm{LB} \mathrm{(1:20)} \mathrm{and} \mathrm{grown} \mathrm{for} \sim 2 \mathrm{hrs}$ at $200 \mathrm{rpm}$ to an $\mathrm{OD}_{600}$ of 0.4 . Using a multipipette, $50 \mu \mathrm{l}$ of biosensor culture was added to each well in a 96-well black cell culture plate, and then $50 \mu \mathrm{l}$ of the crude extract was added to each well and mixed by pipette action. The plate was incubated at $37^{\circ} \mathrm{C}$ for $1 \mathrm{hr}$ without shaking before luminescence was read using a Veri$\operatorname{tas}^{\mathrm{TM}}$ Microplate Luminometer (Promega Corporation, Sunnyvale, CA). Measurement of SA with HPLC was done as described by Verberne et al. [11]. Briefly, 0.1 $\mathrm{g}$ tissues were ground in liquid nitrogen and extracted with $1 \mathrm{~mL}$ of $90 \%$ methanol. After centrifugation at $14,000 \mathrm{~g}$ for $10 \mathrm{~min}$, the supernatant was transferred into a microcentrifuge tube. The pellet was extracted with $0.5 \mathrm{~mL}$ of $100 \%$ methanol and the supernatant was transferred to the same tube and dried in a speed vacuum to final volume of $\sim 50 \mu \mathrm{L}$. The residue was resuspended to $500 \mu \mathrm{L}$ with hydrolysis buffer $(0.1 \mathrm{M}$ sodium acetate buffer, $\mathrm{pH}$ 5.5). The mixture was equally split into two microcentrifuge tubes [one for free SA, the other for glucose conjugated SA (salicylic acid 2-O$\beta$-D-glucoside or SAG)]. For SAG, 10 units of $\beta$-glucosidase were added to the tube. After incubation at $37^{\circ} \mathrm{C}$ for $1.5 \mathrm{hr}$, an equal volume of $10 \%$ TCA was added to both tubes. After centrifugation at $14,000 \mathrm{~g}$ for $10 \mathrm{~min}$, the supernatant was transferred to a fresh tube and partitioned with $1 \mathrm{~mL}$ extraction solvent (1 ethylacetate: 1 cyclohexane). The top organic phase was transferred to a new tube, and dried in a speed vacuum to final volume $\sim 25 \mu \mathrm{L}$. The residue was resuspended to 0.25 $\mathrm{mL}$ with $0.2 \mathrm{M}$ sodium acetate buffer ( $\mathrm{pH} 5.5$ ). After centrifugation at $14,000 \mathrm{~g}$ for $10 \mathrm{~min}$, the supernatant was used for HPLC analysis. The sample was eluted with $0.2 \mathrm{M}$ sodium acetate buffer $\mathrm{pH} 5.5$ in $10 \%$ methanol at a flow-rate of $0.80 \mathrm{~mL} / \mathrm{min}$. 


\section{Statistical methods}

All statistical analyses were performed with the data analysis tools (t-TEST: Two Samples Assuming Unequal Variances) in Microsoft Excel of Microsoft Office 2004 for Macintosh.

\section{Additional material}

Additional file 1: Detailed protocol for identification of SA metabolic mutants using the direct boiling method.

\section{Acknowledgements}

We thank Dr. Hui Wang (NERC/Centre for Ecology and Hydrology-Oxford, Oxford, UK) for the SA biosensor strain Acinetobacter sp. ADPWH_lux, and Drs. William Gurley and Sixue Chen (University of Florida, FL) for access to

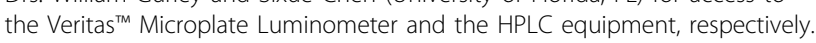
This work was supported by a grant from the Herman Frasch Foundation for Chemical Research and a grant from the National Science Foundation (IOS0842716) awarded to Z.M., and publication of this article was funded in part by the University of Florida Open-Access Publishing Fund.

\section{Authors' contributions}

$G M, R C, Y D, D S$, and $X Z$ performed the experiments. ZM designed the project, wrote the manuscript, and is the PI of the laboratory. All authors read and approved the final manuscript.

\section{Competing interests}

The authors declare that they have no competing interests.

Received: 24 August 2010 Accepted: 23 September 2010 Published: 23 September 2010

\section{References}

1. Durrant WE, Dong X: Systemic acquired resistance. Annu Rev Phytopathol 2004, 42:185-209.

2. Raskin I: Role of salicylic acid in plants. Annu Rev Plant Physiol Plant Mol Biol 1992, 43:439-463.

3. Malamy J, Carr JP, Klessig DF, Raskin I: Salicylic acid: a likely endogenous signal in the resistance response of tobacco to viral infection. Science 1990, 250:1002-1004.

4. Métraux JP, Signer H, Ryals J, Ward E, Wyss-Benz M, Gaudin J, Raschdorf K, Schmid E, Blum W, Inverardi B: Increase in salicylic acid at the onset of systemic acquired resistance in cucumber. Science 1990, 250:1004-1006.

5. Gaffney $T$, Friedrich $L$, Vernooij B, Negrotto D, Nye G, Uknes S, Ward E, Kessmann H, Ryals J: Requirement of salicylic acid for the induction of systemic acquired resistance. Science 1993, 261:754-756.

6. White RF: Acetylsalicylic acid (aspirin) induces resistance to tobacco mosaic virus in tobacco. Virology 1979, 99:410-412.

7. Ryals JA, Neuenschwander UH, Willits MG, Molina A, Steiner H-Y, Hunt MD: Systemic acquired resistance. Plant Cell 1996, 8:1809-1819.

8. Nawrath C, Métraux J-P: Salicylic acid induction-deficient mutants of Arabidopsis express $P R-2$ and $P R-5$ and accumulate high levels of camalexin after pathogen inoculation. Plant Cell 1999, 11:1393-1404.

9. Nawrath C, Heck S, Parinthawong N, Métraux J-P: EDS5, an essential component of salicylic acid-dependent signaling for disease resistance in Arabidopsis, is a member of the MATE transporter family. Plant Cell 2002, 14:275-286.

10. Wildermuth MC, Dewdney J, Wu G, Ausubel FM: Isochorismate synthase is required to synthesize salicylic acid for plant defence. Nature 2001, 414:562-565.

11. Verberne MC, Brouwer N, Delbianco F, Linthorst HJ, Bol JF, Verpoorte R: Method for the extraction of the volatile compound salicylic acid from tobacco leaf material. Phytochem Anal 2002, 13:45-50.

12. Aboul-Soud MAM, Cook K, Loake GJ: Measurement of salicylic acid by a high-performance liquid chromatography procedure based on ionexchange. Chromatographia 2004, 59:129-133.
13. Huang WE, Wang $H$, Zheng $H$, Huang L, Singer AC, Thompson I, Whiteley AS: Chromosomally located gene fusions constructed in Acinetobacter sp. ADP1 for the detection of salicylate. Environ Microbiol 2005, 7:1339-1348.

14. Meighen EA: Bacterial bioluminescence: organization, regulation, and application of the lux genes. FASEB J 1993, 7:1016-1022.

15. Defraia $C T$, Schmelz EA, Mou Z: A rapid biosensor-based method for quantification of free and glucose-conjugated salicylic acid. Plant Methods 2008, 4:28.

16. Cao H, Bowling SA, Gordon S, Dong X: Characterization of an Arabidopsis mutant that is nonresponsive to inducers of systemic acquired resistance. Plant Cell 1994, 6:1583-1592.

17. Delaney TP, Friedrich L, Ryals JA: Arabidopsis signal transduction mutant defective in chemically and biologically induced disease resistance. Proc Natl Acad Sci USA 1995, 92:6602-6606.

18. Schmelz EA, Engelberth J, Alborn HT, O'Donnell P, Sammons M, Toshima H, Tumlinson JH: Simultaneous analysis of phytohormones, phytotoxins, and volatile organic compounds in plants. Proc Natl Acad Sci USA 2003, 100:10552-10557.

19. Cao H, Glazebrook J, Clark JD, Volko S, Dong X: The Arabidopsis NPR1 gene that controls systemic acquired resistance encodes a novel protein containing ankyrin repeats. Cell 1997, 88:57-63.

20. Shah J, Tsui F, Klessig DF: Characterization of a salicylic acid-insensitive mutant (sai1) of Arabidopsis thaliana identified in a selective screen utilizing the SA-inducible expression of the tms 2 gene. Mol Plant-Microbe Interact 1997, 10:69-78.

21. Ryals J, Weymann K, Lawton K, Friedrich L, Ellis D, Steiner H-Y, Johnson J, Delaney TP, Jesse T, Vos P, et al: The Arabidopsis NIM1 protein shows homology to the mammalian transcription factor inhibitor IkB. Plant Cell 1997, 9:425-439.

22. Malamy J, Klessig DF: Salicylic acid and plant disease resistance. Plant J 1992, 2:643-654.

23. Loake G, Grant M: Salicylic acid in plant defence-the players and protagonists. Curr Opin Plant Biol 2007, 10:466-472.

24. Weigel D, Glazebrook J: Arabidopsis: A Laboratory Manual. Cold Spring Harbor, New York: Cold Spring Harbor Laboratory Press 2002, 24-26.

25. Clarke JD, Liu Y, Klessig DF, Dong X: Uncoupling PR gene expression from NPR1 and bacterial resistance: Characterization of the dominant Arabidopsis cpr6-1 mutant. Plant Cell 1998, 10:557-569.

doi:10.1186/1746-4811-6-21

Cite this article as: Marek et al:: A high-throughput method for isolation of salicylic acid metabolic mutants. Plant Methods 2010 6:21.

\section{Submit your next manuscript to BioMed Central and take full advantage of:}

- Convenient online submission

- Thorough peer review

- No space constraints or color figure charges

- Immediate publication on acceptance

- Inclusion in PubMed, CAS, Scopus and Google Scholar

- Research which is freely available for redistribution 